\title{
MODELING PCB ASSEMBLY LINES IN EMS PROVIDER'S ENVIRONMENT: INTEGRATING PRODUCT DESIGN INTO SIMULATION MODELS
}

\author{
Jing Li \\ TE Connectivity \\ 301 Constitution Drive \\ Menlo Park, CA, USA
}

\author{
Nagen Nagarur \\ Binghamton University \\ 4400 Vestal Parkway East \\ Vestal, NY, USA
}

\author{
Krishnaswami Srihari \\ Binghamton University \\ 4400 Vestal Parkway East \\ Vestal, NY, USA
}

\begin{abstract}
The manufacturing pattern of most Electronic Manufacturing Services (EMS) suppliers in US has transformed to accommodate a high mix and low volume environment. Printed Circuit Board (PCB) assembly at EMS is characterized as 'product oriented production': based on product designs, assemblies are processed with different routings, while operation times and process yields also vary depending on the complexity of products. Therefore, in order to simulate PCB assembly line, it is necessary to combine design information into simulation models. This research endeavor is focused on integrating design factors into a planning system, which is developed based on Discrete Event Simulation (DES) modeling. By applying this proposed system, EMS suppliers can effectively plan the required manufacturing resources, predict production cycle time and 'optimize' resource deployment for a specific product. This architecture can significantly reduce the uncertainties of predictions that are caused by product mixes and provide customized production profile for individual product.
\end{abstract}

\section{INTRODUCTION}

Due to the nature of contract manufacturing, most EMS production can be described as high mix and low to medium volume (Ramakrishnan, Parimoo, and Srihari 2005). EMS suppliers need to achieve two key goals: (i) meeting the delivery commitment to customers, and (ii) reducing production cost by enhancing the utilization of resources (Ramakrishnan, Parimoo, and Srihari 2005; Sivakumar et al. 2004). In order to achieve these goals, careful production planning should be carried out for each batch of products. For instance, production lead time should be estimated ahead of time for the purpose of determining the order and date to launch new products; resource allocation should be 'optimized' in order to enhance the utilization of both equipment and labor resources.

Since the PCB assembly process consists of a large number of process steps, random machine failures and resource constraints, commercial software such as Enterprise Resource Planning (ERP) systems or other analytical models based on static calculation have limited ability of providing realistic solutions for day-to-day production processes. Modeling and simulation, on the other hand, can explicitly capture these dynamic impacts and is applied as a principle methodology for analyzing and modeling PCB assembly lines (Diwe et al. 2002; Potoradi, Mason, and Fowler 2002). 


\section{Li, Nagarur, and Srihari}

Many research endeavors have been carried out to model PCB assembly line and also aim to address some unique features of PCB assembly production, such as resource constraints during production, impacts of labor activities, and frequent machine failures, etc. (Mukkamala, Smith, and Valenzuela 2003; Seppanen 2005). However, one of the most significant characteristics of PCB assembly production has been overlooked - product oriented production. For PCB assembly production, production plan needs to be generated according to a specific product, because different products can be quite different in terms of manufacturing resource requirements and production lead time (Srihari and Emerson 1990). Product designs define the whole manufacturing processes and basically determine production routings, operation times and process yields. Neglecting the differences of products in a planning system would significantly undermine the accuracy of predicted results. Essentially, a simulation model with fixed configurations and parameter settings (operation times and yields) is difficult or impossible to fit the scenario of high variety of products unless assuming that all the products are the same.

This research endeavor focuses on developing a prototype production planning system based on DES modeling that is applied in PCB assembly domain. The main objective of this study is to develop a system in order to combine product designs with a simulation model and make it adjustable for different products. Based on this system, EMS suppliers can efficiently allocate the required manufacturing resources, predict production cycle time and 'optimize' resource deployment for a specific product.

\section{BACKGROUND}

At an EMS provider, when a new order is placed, product information, including batch size, Computer Aided Design (CAD) files, Gerber files, Bill of Materials (BOM), and assembly process requirements, is provided by the customers. According to assembly information and customer requirements, manufacturing engineers can determine process flow and work contents at each workstation. Production routings and work contents are determined principally based on product design and additional customer requirements. For example, according to CAD data, engineers can decide whether this product needs single-side or double-side surface mount assembly, and determine whether wave soldering or press-fit operations are required depending on through-hole component types. As shown in Figure 1, based on designs, products are processed in different workstations with different yields and operation times.

\begin{tabular}{|c|c|c|}
\hline Type of Products & Key Operation Steps & $\begin{array}{c}\text { Operation Time } \text { Yield at } \\
\text { the workstations }\end{array}$ \\
\hline 800 다 & $\begin{array}{l}\cdot \text { SMT Top } \\
\cdot \text { Test (X-ray, ICT, etc) }\end{array}$ & $\begin{array}{l}\text { Depends on work content } \\
\text { ( Types of components \& } \\
\text { number of components) }\end{array}$ \\
\hline 5 & $\begin{array}{l}\cdot \text {-SMT Bottom } \\
\cdot \text {-SMT Top } \\
\cdot \text {-Test (X-ray, ICT, etc) }\end{array}$ & $\begin{array}{l}\text { Depends on work content } \\
\text { ( Types of components \& } \\
\text { number of components) }\end{array}$ \\
\hline & $\begin{array}{l}\text { •SMT Bottom } \\
\text { •SMT Top } \\
\text { •Wave Soldering } \\
\text { •Test (X-ray, ICT, etc) }\end{array}$ & $\begin{array}{l}\text { Depends on work content } \\
\text { ( Types of components \& } \\
\text { number of components) }\end{array}$ \\
\hline & $\begin{array}{l}\cdot \text { SMT Bottom } \\
\cdot \text { SMT Top } \\
\cdot \text { Wave Soldering } \\
\cdot \text { Press-fit } \\
\cdot \text { Test (X-ray, ICT, etc) }\end{array}$ & $\begin{array}{l}\text { Depends on work content } \\
\text { ( Types of components \& } \\
\text { number of components) }\end{array}$ \\
\hline
\end{tabular}

Figure 1: Production depends on assembly designs 


\section{Li, Nagarur, and Srihari}

In terms of configuration of a system, since it is impractical to build individual model for each product, a simulation model developed for an EMS facility should be able to be adjustable correspondingly to accommodate defined routings. A planning system developed for PCB assembly production must have the capability to identify the required machines and assembly lines, and re-connect all of the selected resources to be a customized configuration for a specific product.

Moreover, operation times and process yields at each work station are also highly dependent on product design (Zhou and Ladhar 2001, Tarhalkar and Srihari 2002). Typically, in the literature, simulation models are generated according to a "standard" routine: in order to determine parameter settings for each operation module, data is either extracted from historical databases of production line under consideration, or by performing time studies during actual manufacturing process. Data, once collected, is fit to a distribution and applied as parameter settings in simulation models. There is no doubt that the models generated in this way can be used to represent a manufacturing system to certain extent, and can be applied for long-term planning purpose. However, when the objective focuses on particular short-term planning goals and the planning system is principally used for guiding daily production by providing a specific manufacturing profile for each product, the inputs that are only based on the general features of a line are not sufficient, especially for PCB assembly manufacturing.

In terms of operation time, most of the machines of a PCB assembly line are precisely controlled with standard operation time. For instance, considering a placement workstation, Product A includes 1000 surface mount components that need to be populated on a circuit board, while product B has only 200 components to be mounted. Each single placement takes a fixed amount of time. Thus, the placement time can be precisely calculated with the information of component types and quantity. If a simulation model is applied without re-initializing the settings of operation time according to this particular product, prediction results might show that product A takes almost the same or even less processing time compared with product $\mathrm{B}$, which is obviously wrong. Additionally, machine time is highly correlated with component types. Placing a fine pitch integrated circuits (IC) component takes a longer time than a normal component, and also placing a high I/O Ball Grid Array (BGA) needs much more time than a passive component. Neglecting the design factors and adopting a randomly generated value following certain distributions, the machine time or cycle time could be far from the reality.

Similarly, yield at each workstation is also highly dependent on product design. The general rule is that increased component complexity increases the chances of defects (Tong 2001). For example, the defect rate of a chip shooter to place 0603 components is as low as $0 \%$, the defect rate averages around $10 \%$ to place 0402 components, and the defect rate could increase to $50 \%$ when placing 0201 components. In this case, the defect rate increases due to a reduction in component size, which requires higher placement accuracy. Thus, using the same machine but placing components with a smaller size can result in more issues and defects. At each operation step, products with defects have to be reworked before being transported to the next workstation. Rework is a time-consuming operation and significantly impacts the production lead time. Therefore, determining an accurate yield value at each processing step is critical to generate a reliable prediction of production lead time. However, so far few studies have applied or incorporated yield prediction models into production planning systems. Simply assigning a fixed yield value without considering product features can result in large inconsistencies between the predicted values and the actual values.

\section{OBJECTIVE}

The focus of this study is to model PCB assembly lines with integration of product design into a planning system. Based on this proposed structure, the planning system is able to customize the analysis and planning for a specific product. In addition, incorporating design information into a production planning system can significantly enhance the accuracy of prediction results, which is especially important for shortterm production planning. Based on this planning system, EMS suppliers can efficiently plan the required manufacturing resources, predict production cycle time and optimize resource deployment in their daily production. 


\section{Li, Nagarur, and Srihari}

\section{METHODOLOGY}

A framework is proposed in this research for integrating product design into simulation models as shown in Figure 2. This framework includes two sections: 1) Discrete Event Simulation (DES) model, and 2) three product information processing modules. Product information processing modules are connected with the simulation model and are applied to pre-process related product documents (CAD and BOM, etc), which are abstracted from ERP systems. Then, the information is transferred to the simulation model to initialize model configuration and parameter settings. Consequently, structure and parameter settings of this simulation model are not fixed, and can be modified and updated based on a particular product via inputs from information processing modules. The simulation model is in the role of only running simulations based on input product information. Production cycle time and resource utilizations are two major performance criteria as system outputs. "What-if" analyses can also be performed based on the simulation model in order to determine best strategies in terms of resource deployment. The following sections primarily include a detailed discussion that pertains to concept and structures of these three information processing modules and interconnection with the simulation model.

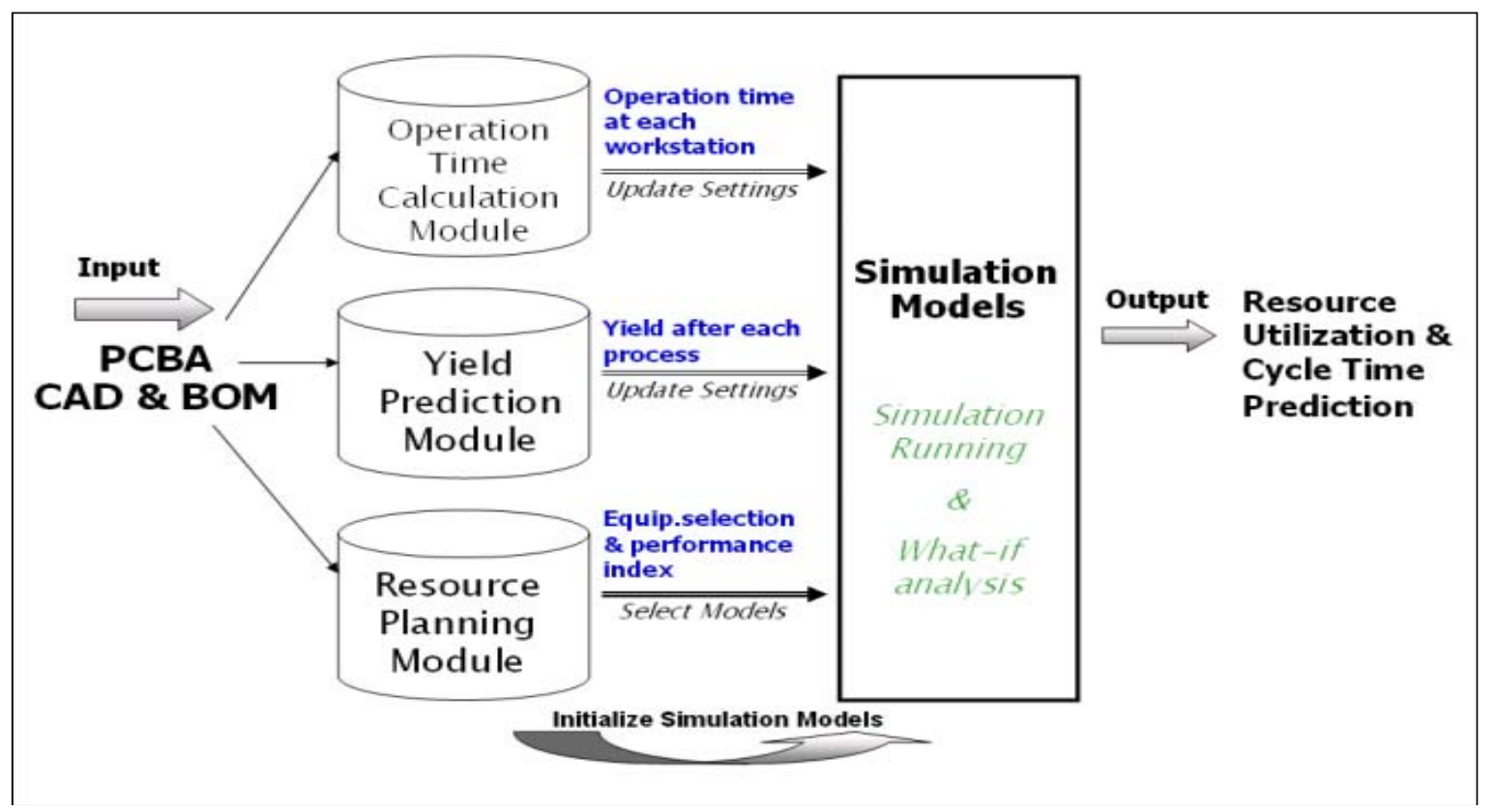

Figure 2: Framework of Integrating Product Design into Planning System

\subsection{Resource Planning - Production Routing Selection in Simulation Models}

Resource Planning Module is used to determine production routings according to CAD data. The routing information generated from this module is connected with simulation models. The simulation models are generated to include every workstation or processing step which can be involved in a PCB assembly process as shown in Figure 3. Each workstation is built independently as a sub-system, and 'Enter' and 'Leave' modules are used as paths to connect the modules together. Products (simulating entities) running in the system can 'select' machines according to the defined routings.

The routing information is defined in the 'Assign' module. The entities of a single product are assigned the same attribute. When these entities enter the system, they will select the workstations and follow the sequences as defined. Hence, each product can have its own production routing as defined. In this way, for a given product, the required manufacturing resources (equipment and operators) can be selected and connected as a customized assembly line as shown in Figure 4. 


\section{Li, Nagarur, and Srihari}

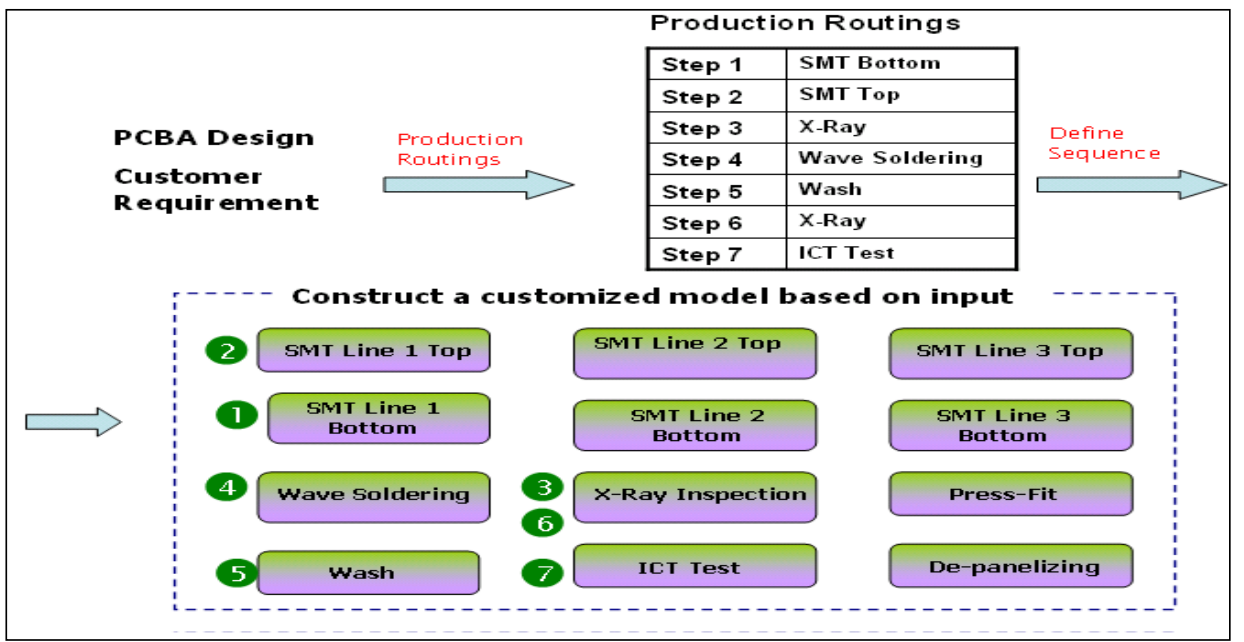

Figure 3: Manufacturing resources selection based on the defined production routing

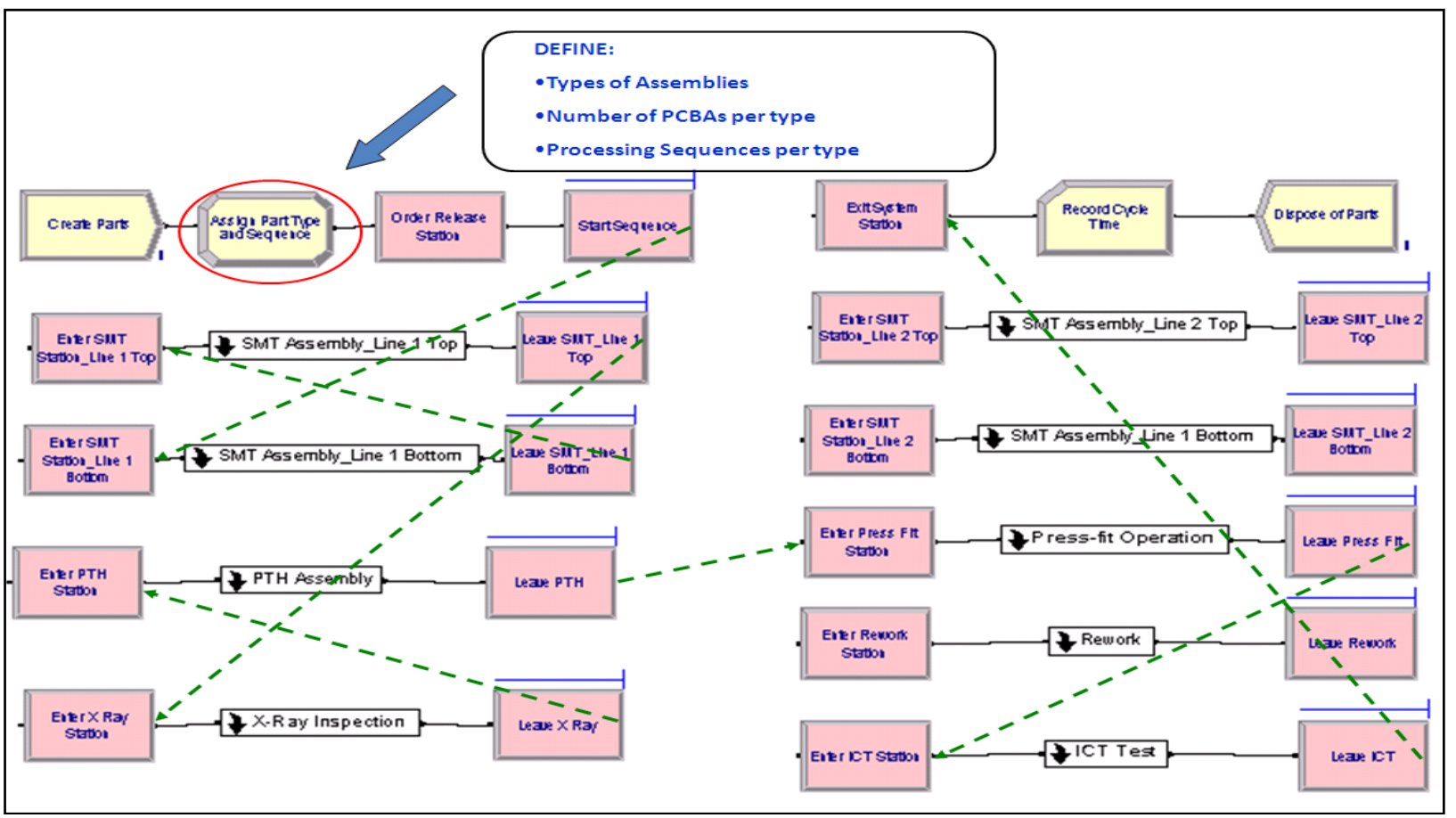

Figure 4: Production routing selection in simulation model

\subsection{Determine Operation Times According to Product Design}

The second component of product information processing section is 'operation time calculation module'. In this study, a PCB assembly operation time calculation template is developed to calculate machine time according to design information (BOM and CAD files). Operation time at each workstation can be calculated and then transferred to the simulation model in order to initialize parameter settings.

All the calculated values are transferred to 'Expression Table' in simulation model, which is linked with machine 'Process' modules as shown in Figure 5. Once values are updated in 'Expression Table,' the settings of machine 'Process' modules simultaneously change to fit this new application. Hence, rather than assuming a fixed value or defining a distribution for operation time, the operation times in the 'Process' modules can be updated continuously for new applications. 


\section{Li, Nagarur, and Srihari}

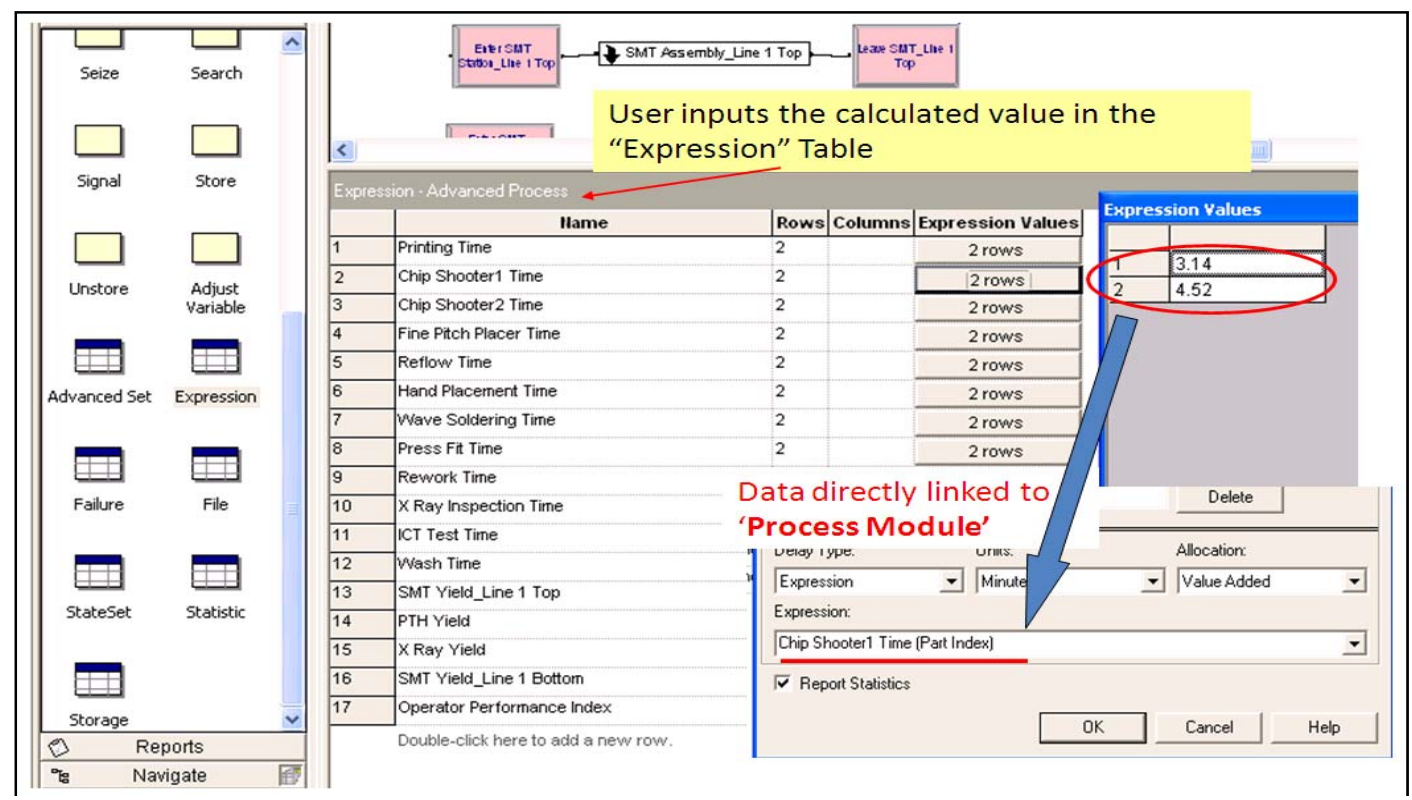

Figure 5: Updating parameter settings based on product information

\subsection{Determine Process Yields According to Product Design}

'Yield Prediction Module' includes a series of yield prediction models for major workstations and provides the input information (yields) to simulation models. In this study, yield prediction models are generated based on stepwise regression analysis and a series of design factors are selected as regressors, such as board dimensions, packaging density, component types and their number, etc. In this study, three steps are used to select regressors: (i) selecting factors based on the knowledge and experiences about PCB assembly; (ii) selecting factors considering the convenience of applications, and (iii) further selecting regressors via stepwise regression analysis. The regression models for principle workstations are shown in Table 1. The predicted yield values are connected with 'Decision' modules of simulation models. Value settings in decision modules of a simulation model can be updated by calculating yield values rather than assuming certain fixed values. At each assembly step (SMT, wave soldering, and press-fit), yield values can be calculated via prediction models and transferred to simulation models in a similar way as operation time.

Table 1: Yield prediction models at main PCB workstations

\begin{tabular}{|c|c|c|}
\hline & Regression Model & $\mathbf{R}^{2}$ \\
\hline SMT & $\begin{array}{l}\text { Yield }=0.981-0.000045(0402)+0.00161 \mathrm{IC}-0.0179 \text { Fine Pitch IC }+0.00719 \\
\text { BGA }-0.0003 \text { LF }+0.00060 \text { Density }-0.0185 \text { Build Times }-0.000001 \\
(0402) * \text { Density }+0.000035(0402) * \text { LF }-0.00643 \text { BGA*LF }+0.0124 \text { Fine-Pitch } \\
I C * \text { LF }-0.00066 \text { BGA*Build Times }\end{array}$ & $92.4 \%$ \\
\hline Wave & $\begin{array}{l}\text { Wave yield }=1.05-0.000905 \text { Thickness }+0.125 \mathrm{LF}+0.013 \text { Number of } \mathrm{TH} \\
\text { Comp.-0.0011Thickness } * \text { LF }-0.0086 \mathrm{LF} * \text { Number of TH Comp. }\end{array}$ & $86.7 \%$ \\
\hline X-Ray & $\begin{array}{l}\text { X-ray Yield }=1.18-0.000393(0402) /(0603)+0.0451 \mathrm{BGA}-0.207 \mathrm{LF}-0.00837 \\
\text { Density }+0.000475(0402) /(0603) * \mathrm{LF}-0.0446 \mathrm{BGA} * \mathrm{LF}\end{array}$ & $90.2 \%$ \\
\hline ICT Test & $\begin{array}{l}\text { Yield at ICT }=1.10-0.00356 \mathrm{IC}+0.0362 \text { Fine Pitch IC }-0.00446 \mathrm{BGA}+ \\
0.000001(0402) /(0603) * \text { Density }+0.00695 \mathrm{BGA} \text { LF }-0.0427 \text { Fine Pitch IC*LF }\end{array}$ & $87.2 \%$ \\
\hline
\end{tabular}

(0402) refers to the quantity of passive components with size as $0.4 \mathrm{~mm} \times 0.2 \mathrm{~mm}$; (0603) refers to the quantity of passive components with size as $0.6 \mathrm{~mm} \times 0.3 \mathrm{~mm}$. 


\section{Li, Nagarur, and Srihari}

\section{CASE STUDY}

In this section, a comparative study based on two different PCB assemblies is conducted to show the impact of product design on predictions of production cycle time and resource utilizations. The analysis in this case study demonstrates the necessity to differentiate products for short-term production planning in PCB assembly domain.

As Figure 6 shows, assembly A and assembly B are two typical PCB assemblies from the same customer. It is obvious that product A and product B are quite different in terms of their structures. The design of assembly A is relatively simple and only needs one-side assembly. The components required to be assembled mainly include two plastics BGA, several IC components and passive components. The total number of components is less than 300 and lead-free processing is required. Compared with Assembly A, the design of assembly B is much more complex. Assembly B not only includes both sides SMT assembly, but also needs wave soldering and press-fit operations for assembling through-hole components. In terms of volume of components, Assembly B needs to assemble more than 5000 components with high variety of component types. The flow chart of Figure 7 shows the production routings for both assemblies. Table 2 show the summary of components for both assemblies which is abstracted from Bill of Materials (BOM).

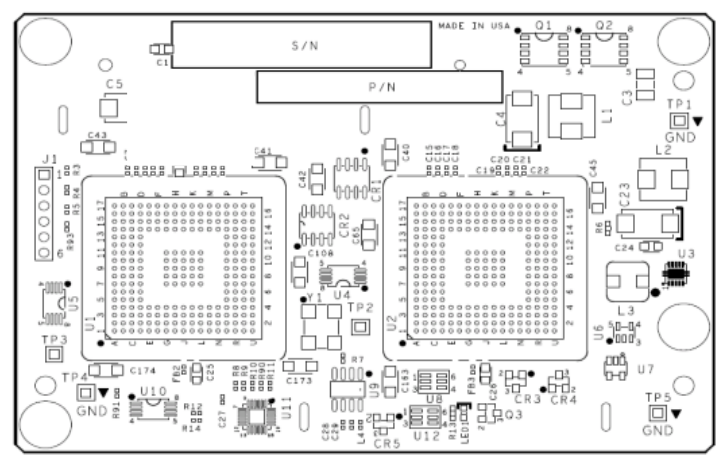

(a) Assembly Drawing of Product A

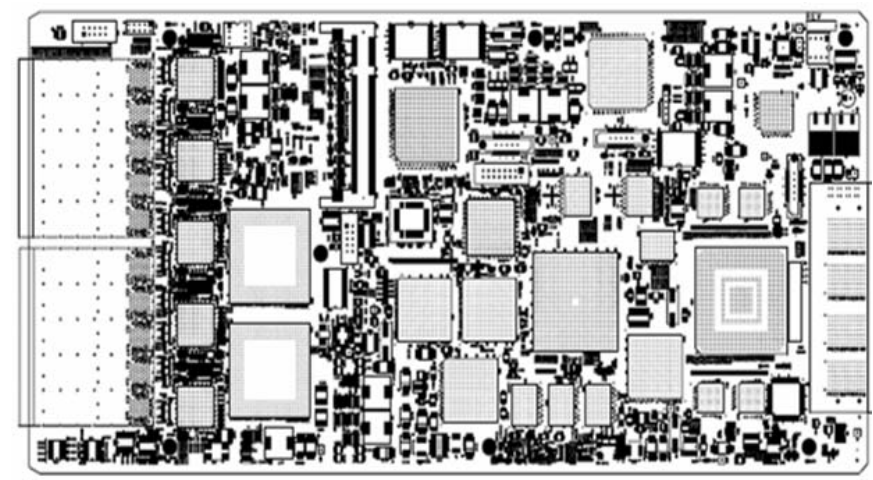

(b) Assembly Drawing of Product B

Figure 6: PCB Assembly CAD Drawings

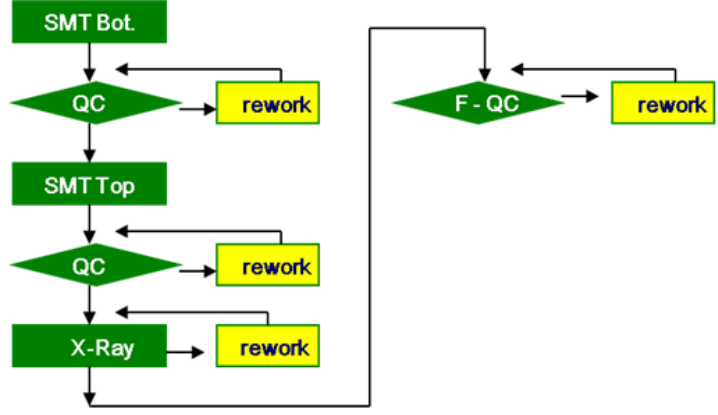

(a) Process Flow Chart of Assembly A

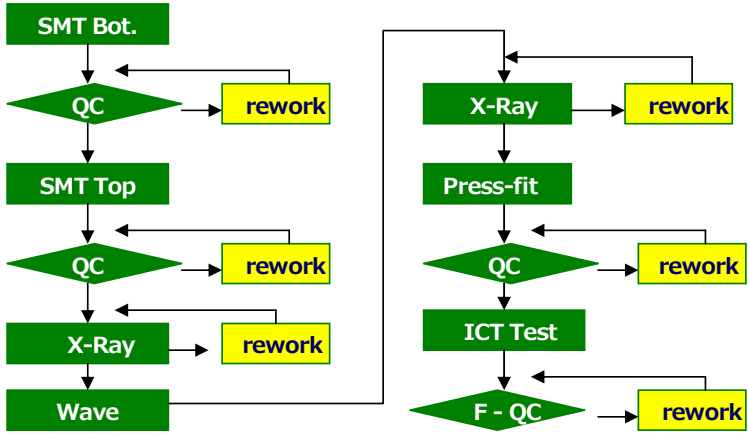

(b) Process Flow Chart of Assembly B

Figure 7: Production Routings

For both assemblies, given a batch size of 200 , the predicted results about production cycle time are shown in Table 3. The average cycle time for Assembly A is $435.27 \mathrm{~min}$ and ranges between $295.49 \mathrm{~min}$ to $877.61 \mathrm{~min}$, and the average cycle time for Assembly B is $1491.33 \mathrm{~min}$ and ranges between $718.82 \mathrm{~min}$ to $2454.48 \mathrm{~min}$. The range of cycle time of assembly A and B is quite different according to the predicted results. According to time measurements on shop floor, cycle time of assembly A is recorded as 7.5 


\section{Li, Nagarur, and Srihari}

hours (450 min) and cycle time of assembly B is recorded as 28 hours (1680 min). Both cycle time measurements are perfectly fitted into the range of predicted cycle time.

Table 2: Component Summaries from BOM

\begin{tabular}{|l|c|c|}
\hline & Top Side & Bottom Side \\
\hline Chip (0402) & 2110 & 2919 \\
\hline Chip(0805,1206) & 465 & 410 \\
\hline Chip (0805,1206) & 13 & 24 \\
\hline PLCC/CONN & 72 & 49 \\
\hline QFP/TSOP & 9 & 1 \\
\hline BGA & 27 & 0 \\
\hline Through-hole Comp. & 4 & \\
\hline Press-fit Comp. & 2 & \\
\hline
\end{tabular}

Table 3: Prediction of Production Cycle Time

\begin{tabular}{cccc}
\hline \multicolumn{4}{c}{ Cycle Time Prediction } \\
\hline Product & Average & Min. Value & Max. Value \\
A & $435.27 \mathrm{~min}$ & $295.49 \mathrm{~min}$ & $877.61 \mathrm{~min}$ \\
B & $1491.33 \mathrm{~min}$ & $718.82 \mathrm{~min}$ & $2453.48 \mathrm{~min}$ \\
\hline
\end{tabular}

This case study demonstrates that product design has a dramatic impact on production cycle time. Actually, it is obvious that an assembly with more complex structure typically requires more operation steps, longer operation time and generates higher defect rates. Clearly, using a simulation model with fixed configuration or parameter settings found in literature it would be difficult to interpret such impacts from product feature differences.

Besides the impact on production cycle time, equipment utilizations in a single assembly line changes when assembling different products. As shown in Figure 8, most of the machines in Product A assembly line have much lower utilization than the ones in product B assembly line. In product B assembly line, chip shooters are the bottleneck machines and determine the production rate. While the chip shooters in product A assembly line have only around 50\% utilization rate. Hence, the differences of products can also make an impact on the equipment utilization and further affect decision making regarding resource deployment.

In this case, it would be appropriate to assign a line with high performance chip shooters for product $\mathrm{B}$ instead of product A so that production output can be increased. This case also shows the significant meaning to integrate product information into a planning system in order to arrange manufacturing resources properly.

\section{CONCLUSIONS}

For PCB assembly production, product design has a dramatic impact on manufacturing process in terms of routing selections, operation times and processing yields. Hence, PCB assembly production is a "product oriented production." This is one of the most important characteristics of PCB assembly production, but this feature has been overlooked in most of simulation models developed in literature.

In this research, several information processing modules have been developed and are used to extract and process PCB assembly design information. These modules work in conjunction with simulation models to continuously initialize the settings of production routings, operation times and processing yields. 


\section{Li, Nagarur, and Srihari}

Simulation models only serve as a test bed to run simulation and 'what-if' analysis. The configuration of the model and parameter settings are all not fixed and can be adjusted for target applications. In this way, the proposed system can be extremely flexible to fit any products precisely and provide the customized production solution for each individual product.

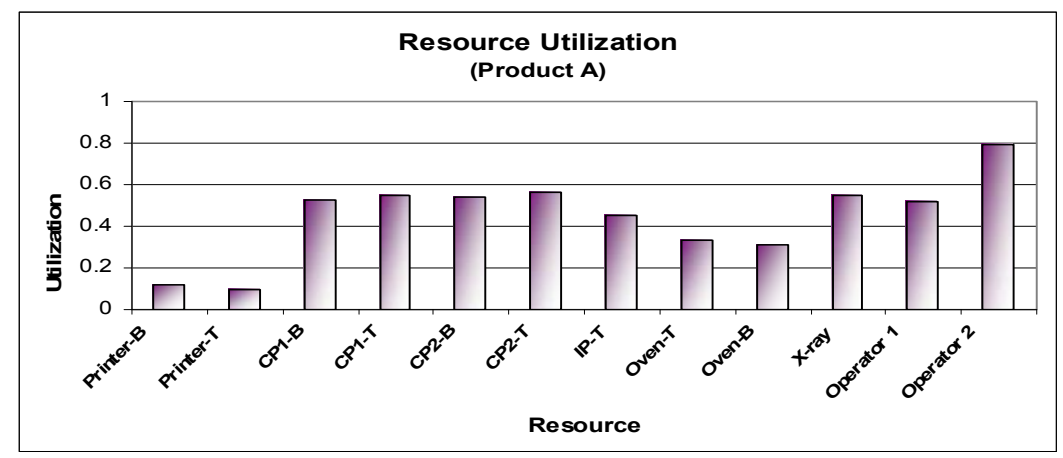

(a) Resource Utilization for Assembly Product A

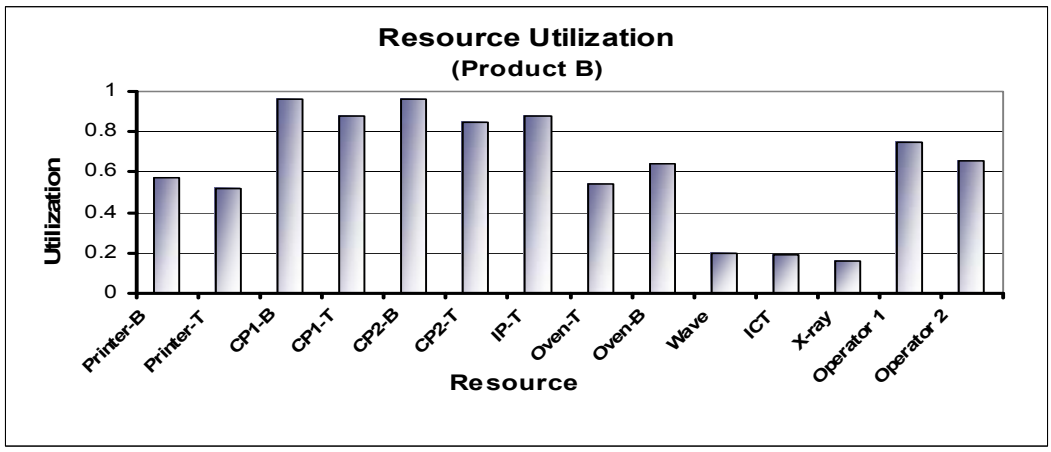

(b) Resource Utilization for Assembly Product B

Figure 8: Analysis of Resource Utilization Depends Upon Products

\section{REFERENCES}

Diwe, P., N. Kini, R. Iyer, and K. Srihari. 2002. "Capacity Requirements Planning in a High Volume, Medium/High Mix EMS Provider's Environment." Proceedings - Pan Pacific 2002, 214-219. Maui, Hawaii.

Mukkamala, P. S., J. S. Smith, and J. F. Valenzuela. 2003. "Designing Reusable Simulation Modules for Electronics Manufacturing Systems." In Proceedings of 2003 Winter Simulation Conference, edited by S. E. Chick, P. J. Sanchez, D. M. Ferrin, and D. J. Morrice, 1281-1289. Piscataway, New Jersey: Institute of Electrical and Electronics Engineers, Inc.

Potoradi, J., S. J. Mason, and J. W. Fowler. 2002. "Using Simulation-Based Scheduling to Maximize Demand Fulfillment in a Semiconductor Assembly Facility." In Proceedings of the 2002 Winter Simulation Conference, edited by E. Yücesan, C. H. Chen, J. L. Snowdon, and J. M. Charnes, 1857-1861. Piscataway, New Jersey: Institute of Electrical and Electronics Engineers, Inc.

Ramakrishnan, S., S. Parimoo, and K. Srihari. 2005. "Best practices for post-ERP implementation an EMS provider." SMTA International, Chicago, IL.

Seppanen, S. M. 2005. "Operator - Paced Assembly Line Simulation." In Proceedings of the 2005 Winter Simulation Conference, edited by M. E. Kuhl, N. M. Steiger, F. B. Armstrong, and J. A. Joines, 1343 -1349. Piscataway, New Jersey: Institute of Electrical and Electronics Engineers, Inc.

Sivakumar, K., K. Srihari, D. Warheit, and A. Gowda. 2004. "Tactical production planning for printed circuit board assembly." Pan Pacific Conference, Oahu, Hawaii, pp. 221-229. 


\section{Li, Nagarur, and Srihari}

Srihari, K., and C. R. Emerson. 1990. "Uncertainty Management in Process Planning for PCB Assembly." Electronic Manufacturing Technology Symposium, Proceedings, 'Competitive Manufacturing for the Next Decade'. IEMT Symposium, Ninth IEEE/CHMT International, 290-296. Washington, DC.

Tarhalkar, A., and K. Srihari. 2002. "Product Cost Estimation Using Activity-Based Costing." SMTA International, Chicago, IL.

Tong, J. J. 2001. "Predicting Circuit Board Assembly Yield from Design Parameters." Master's Thesis, University of Colorado.

Zhou, X., and H. Ladhar. 2001. "Quantifying the Effect of the Factors that Influence Yield in an EMS Environment." SMTA International, Chicago, IL.

\section{AUTHOR BIOGRAPHIES}

JING LI is an advanced manufacturing engineer at TE Connectivity, CA. She received the Ph.D. in System Science and Industrial Engineering at State University of New York, Binghamton. Her research interests focus on PCB assembly process development, production planning, Lean \& 6 Sigma. Her email address is ljing2@binghamton.edu.

NAGEN NAGARUR is an Associate Professor and Department Chair in the Department of System Science and Industrial Engineering at State University of New York, Binghamton. His research interests are reliability of micro-electronic components, quality control and supply chain modeling. His email address is nnagarur@binghamton.edu.

KRISHNASWAMI SRIHARI is a Distinguished Professor and Dean of Thomas J. Watson School of Engineering and Applied Science. He is the Director of Watson Institute for Systems Excellence (WISE). Dr. Srihari's research is focused on the electronics manufacturing domain. His email address is srihari@binghamton.edu. 